\title{
Plasma homovanillic acid and treatment response in a large group of schizophrenic patients*
}

\author{
Wen-Ho Chang ${ }^{\text {a,b }}$, Hai-Gwo Hwu ${ }^{\text {ba }}$, Teng-Yi Chen ${ }^{a}$, Shi-Kwang Lin ${ }^{a}$, For-Wei Lung ${ }^{c}$, Horng \\ Chen ${ }^{\mathrm{c}}$, Wen-Long Lin ${ }^{\mathrm{c}}$, Wei-Herng Hu${ }^{\mathrm{a}}$, Hsin-Nan Lin ${ }^{\mathrm{b}, \mathrm{a}}$ and Ching-Piao Chien ${ }^{\mathrm{a}, \mathrm{b}}$ \\ ${ }^{a}$ Laboratory of Biological Psychiatry and Department of Adult Psychiatry, Taipei City Psychiatric Center, Taipei, Taiwan and \\ ${ }^{\mathrm{b}}$ Department of Psychiatry, Medical College, National Taiwan University, Taipei, Taiwan and ${ }^{\mathrm{c}}$ Military 818 Psychiatric Hospital, \\ Taipei, Taiwan
}

(Received 12 September 1992; revision received 26 January 1993; accepted 28 January 1993)

Plasma levels of homovanillic acid (pHVA), a metabolite of dopamine, were measured in ninety-five Chinese schizophrenic patients free of neuroleptics for at least four weeks. These patients were treated with classical antipsychotics for six weeks. Pretreatment pHVA was positively correlated with the subsequent clinical response $(r=0.408, p<0.0001)$. Good responders (BPRS improvement $\geqslant 50 \%, n=47)$ had higher pretreatment pHVA levels than poor responders (BPRS improvement $<50 \%, n=48)(15.7 \pm 8.4 \mathrm{ng} / \mathrm{ml}$ versus $9.9 \pm 3.7 \mathrm{ng} / \mathrm{ml}, p<0.0001)$. A higher than $15 \mathrm{ng} / \mathrm{ml}$ pretreatment $\mathrm{pHVA}$ level was associated with a more consistent clinical response to the subsequent treatment. Using a pHVA level of $12 \mathrm{ng} / \mathrm{ml}$ as a demarcation point, $72 \%$ of patients (34 of 47 ) who had pHVA $\geqslant 12$ responded whereas $65 \%$ (31 of 48 ) who had $<12$ did not respond (chi-square $=13.02, p<0.0001$ ). These results suggest that higher pretreatment pHVA levels may predict a better clinical response to antipsychotics. Based upon the pHVA findings, two hypothetical subtypes of schizophrenia are proposed.

Key words: Plasma homovanillic acid; Neuroleptic response; Subtype; (Schizophrenia)

\section{INTRODUCTION}

The dopamine (DA) hypothesis of schizophrenia which proposes that enhanced central dopaminergic activity is causally related to this mental disorder has been one of the most important and enduring concepts in biological psychiatry in the last two decades. The measurement of the DA metabolite homovanillic acid (HVA) in body fluids has been one of the most widely used strategies for studying aspects of DA function in neuropsychiatric disorders. This approach has been based,

Correspondence to: Wen-Ho Chang, Laboratory of Biological Psychiatry, Taipei City Psychiatric Center, 309 Sung-Te Road Taipei, Taiwan 10510, ROC.

* Presented at the 7th International Catecholamine Symposium, June 22-26, 1992. in part, on the possibility that metabolite production reflects neurotransmitter release and turnover in the brain. Even though no more than $25 \%$ of plasma HVA (pHVA) appears to be of central origin according to current estimates (Amin et al., 1992), plasma may still be the most useful body fluid for HVA measurement as a correlate of clinical state. Based on both lines of reasoning, pHVA studies in psychiatric patients have been conducted in a number of research centers (Bowers et al., 1984; Pickar et al., 1984; Davis et al., 1985; Chang et al., 1988; Davila et al., 1988).

Several reports of pHVA concentrations in schizophrenic patients have produced interesting, yet inconsistent, results. Pickar et al. (1984) found that pHVA levels in schizophrenic patients are significantly higher than those in normal control volunteers, whereas Davidson and Davis (1988) reported the reverse. In addition, significant positive correla- 
tions between baseline pHVA levels and symptom severity have been reported by Pickar et al. (1984) and Davis et al. (1985) but not by others (Bowers et al., 1984; Chang et al., 1990; Javaid et al., 1990; Mazure et al., 1991). Differences in patient population and study design methods could potentially account for the different findings. In contrast, a more consistent finding is that pretreatment pHVA levels are associated with clinical outcome in psychiatric patients (Bowers, 1991; Bowers et al., 1984, 1987; Chang et al., 1990; Davidson et al., 1991; Mazure et al., 1991) although not all studies agree (Javaid et al., 1990). We have previously reported that pretreatment levels of pHVA in a group of schizophrenic patients $(n=22)$ who had a relatively favorable clinical response to a fixeddose $(20 \mathrm{mg} /$ day $)$ haloperidol treatment are significantly higher than those in poor responders $(n=11)$ (Chang et al., 1990). Moreover, a timedependent decrement in pHVA in good responders but not in poor responders was found in our previous studies (Chang et al., 1988, 1990). Based upon these findings, we have suggested that two biologically distinct subtypes can be differentiated among schizophrenic patients. In the present study we replicate and extend our initial observations to a new and larger group of patients who were treated with a variable dose of haloperidol or flupenthixol $(n=62)$. Combined with the 33 subjects on fixed-dose haloperidol, this study provides data in a total of 95 schizophrenic patients.

\section{METHODS}

Subjects were ninety-five physically healthy Chinese patients (59 men aged 19-52 and 36 women aged 18-51) who were admitted to the psychiatric wards of Taipei City Psychiatric Center, National Taiwan University Medical Center and Military 818 Psychiatric Center from April 1985 to March 1990. All patients met DSM-III criteria for schizophrenic disorder (American Psychiatric Association, 1980), gave informed consent to participate in the study, and had not received oral antipsychotics for at least 4 weeks and depot antipsychotics for at least 3 months prior to study entrance. The patients were kept on a lowmonoamine and caffeine-restricted diet throughout the study. One to three blood samples were obtained from the subjects after an overnight fast between 06.30 and $07.00 \mathrm{~h}$ on the successive 3 days before treatment. All patients then received a 6-week course of antipsychotic drugs. The drug trials involved three groups of patients: a previously reported fixed-dose haloperidol (20 mg/day) (Haldol, Janssen Pharmaceutica, Beerse, Belgium) group $(n=33)$ (Chang et al., $1990)$, a variable-dose haloperidol group $(n=43)$, and a variable-dose flupenthixol (Fluanxol, A/S Lundbeck, Copenhagen, Denmark) group $(n=19)$. The dosages of the variable-dose groups were titrated on a clinical basis in the first two weeks and kept at the same levels during the subsequent 4 wceks. The dose ranges were 10 to $30 \mathrm{mg} / \mathrm{day}$ for haloperidol and 6 to $24 \mathrm{mg} /$ day for flupenthixol, respectively. Anticholinergics and benzodiazepines were permitted during the six-week protocol.

Pretreatment psychotic symptoms were rated using the Brief Psychiatric Rating Scale (BPRS) (Overall and Gorham, 1962) on one of the 3 days before the initial neuroleptic adminstration; ratings were repeated every 2 weeks during treatment. A total score was based on the sum of 16 items using a $0-6$ scale. Patients with $\geqslant 50 \%$ improvement in the total score by week 6 of treatment were considered as 'good responders'; those with $<50 \%$ improvement were 'poor responders'.

One to four steady-state blood samples for plasma drug monitoring were also obtained from most patients $(n=90)$.

Venous blood was drawn in heparinized tubes. The plasma samples, separated in a refrigerated centrifuge, were stored in a $-60^{\circ} \mathrm{C}$ freezer until assayed. Plasma free HVA was determined with high performance liquid chromatography using electrochemical detection (HPLC/ECD) (Chang et al., 1983). The sensitivity of this method is 0.5 $\mathrm{ng} / \mathrm{ml}$. The intra- and interassay coefficients of variation for this determination are $2.2 \%$ and $6.3 \%$, respectively. Plasma concentrations of haloperidol (Korpi et al., 1983; Chang et al., 1989) and flupenthixol (Wu et al., 1978) were measured with HPLC/ECD. The sensitivity is $0.5 \mathrm{ng} / \mathrm{ml}$ or less for both assays. The intra- and interassay coefficients of variation are $4 \%$ and $12 \%$ for haloperidol and $4 \%$ and $15 \%$ for flupenthixol, respectively.

Statistical analysis was carried out by means of 
the Student's $t$-test, Pearson's product-moment correlation and the chi-square test.

\section{RESULTS}

Forty-seven patients were rated as having a good clinical response, and 48 a poor clinical response. As shown in Table 1, the two groups did not differ significantly in terms of age, gender, or pretreatment BPRS rating. However, the pretreatment pHVA in the good responder group was significantly higher than that in the poor responder group $(15.7 \pm 8.4 \mathrm{ng} / \mathrm{ml}$ versus $9.9 \pm 3.7 \mathrm{ng} / \mathrm{ml}, t=$ $4.44, p<0.0001)$. Moreover, there was a positive correlation between baseline pHVA and clinical improvement after 6 weeks of antipsychotic treatment $(r=0.408, p<0.0001)$ (Fig. 1). Nineteen of twenty-one patients with $>15 \mathrm{ng} / \mathrm{ml}$ baseline pHVA values were good responders. However, more than one-half of the good responders had baseline pHVA values of $<15 \mathrm{ng} / \mathrm{ml}(26 / 47)$. Using a pHVA level of $12 \mathrm{ng} / \mathrm{ml}$ as a demarcation point (Mazure et al., 1991), 72\% of patients $(34 / 47)$ who had $\mathrm{pHVA} \geqslant 12$ responded whereas $65 \%(31 / 48)$ who had $<12$ did not respond (Chi-Square= 13.02, $\mathrm{df}=1, p<0.0001$ ) (Table 2).

Data on pHVA and clinical response grouped according to fixed-dose and variable-dose schedules are presented in Table 3. Although haloperidol dosages and plasma levels in poor responders were significantly higher than those in good responders $(0.48 \pm 0.13 \mathrm{mg} / \mathrm{kg} /$ day versus $0.32 \pm 0.15 \mathrm{mg} / \mathrm{kg} /$ day, $t=2.932, p<0.01$ and $25.9 \pm 13.5 \mathrm{ng} / \mathrm{ml}$ versus $16.4 \pm 10.9 \mathrm{ng} / \mathrm{ml}, t=2.627, p<0.05$ ) in the variable-dose group, higher baseline pHVA levels in

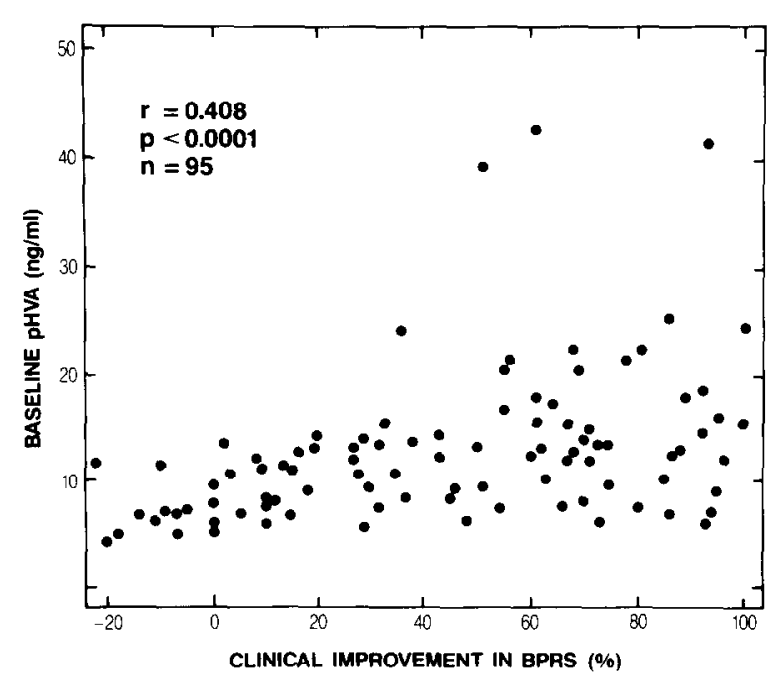

Fig. 1. Correlation between baseline pHVA levels and clinical improvements after 6 weeks of antipsychotic treatment.

good responders and lower levels in poor responders were found in both fixed and variable dose groups: $17.4 \pm 8.8 \mathrm{ng} / \mathrm{ml}$ versus $11.4 \mathrm{ng} / \mathrm{ml}$ $(p<0.05)$ and $14.0 \pm 7.8 \mathrm{ng} / \mathrm{ml}$ versus $9.3 \pm 3.0$ $\mathrm{ng} / \mathrm{ml}(p<0.005)$.

\section{DISCUSSION}

Ninety-five schizophrenic patients were divided into two groups on the basis of their clinical outcome following 6 weeks of antipsychotic treatment. Patients who responded had higher pretreatment pHVA levels than non-responders. A higher than $15 \mathrm{ng} / \mathrm{ml}$ pretreatment $\mathrm{pHVA}$ level was associated with a more consistent clinical response to

TABLE 1

Data on schizophrenic patients grouped according to clinical response to neuroleptic treatment (mean $\pm S D$ )

\begin{tabular}{llll}
\hline & $\begin{array}{l}\text { Good responders } \\
(n=47)\end{array}$ & $\begin{array}{l}\text { Poor responders } \\
(n=48)\end{array}$ & Difference \\
\hline Age (years) & $29.6 \pm 8.3$ & $30.9 \pm 9.1$ & NS \\
Sex (M/F) & $28 / 19$ & $31 / 17$ & NS \\
Baseline BPRS & $36.5 \pm 9.8$ & $36.8 \pm 9.8$ & NS \\
BPRS improvement (\%) & $74.4 \pm 14.8$ & $14.5 \pm 19.4$ & $p<0.0001$ \\
Baseline pHVA (ng/ml) & $15.7 \pm 8.4$ & $9.9 \pm 3.7$ & $p<0.0001$ \\
\hline
\end{tabular}

BPRS, brief psychiatric rating scale; pHVA, plasma homovanillic acid. 
TABLE 2

Comparison of plasma homovanillic acid and clinical response between two studies

\begin{tabular}{|c|c|c|c|c|}
\hline \multirow[t]{3}{*}{ Study } & \multicolumn{4}{|c|}{ Baseline plasma homovanillic acid } \\
\hline & \multicolumn{2}{|l|}{$\geqslant 12 \mathrm{ng} / \mathrm{ml}$} & \multicolumn{2}{|l|}{$<12 \mathrm{ng} / \mathrm{ml}$} \\
\hline & Responder & Nonresponder & Responder & Nonresponder \\
\hline Mazure et al. (1991) & $14(75 \%)$ & $6(25 \%)$ & $5(29 \%)$ & $12(71 \%)$ \\
\hline This study & $34(72 \%)$ & $13(28 \%)$ & $17(35 \%)$ & $31(65 \%)$ \\
\hline
\end{tabular}

TABLE 3

Data on schizophrenic patients grouped according to fixed-dose and variable-dose schedules and clinical response to neuroleptic treatment (mean $\pm S D)$

\begin{tabular}{|c|c|c|c|c|}
\hline \multirow[t]{2}{*}{ Variable } & \multicolumn{2}{|c|}{ Fixed-dose $(n=33)$} & \multicolumn{2}{|c|}{ Variable-dose $(n=62)$} \\
\hline & $\begin{array}{l}\text { Good } \\
\text { responders } \\
(n=22)\end{array}$ & $\begin{array}{l}\text { Poor } \\
\text { responders } \\
(n=11)\end{array}$ & $\begin{array}{l}\text { Good } \\
\text { responders } \\
(n=26)\end{array}$ & $\begin{array}{l}\text { Poor } \\
\text { responders } \\
(n=36)\end{array}$ \\
\hline Baseline pHVA (ng/ml) & $17.4 \pm 8.8$ & $11.4 \pm 5.0^{\mathrm{a}}$ & $14.0 \pm 7.8$ & $9.3 \pm 3.0^{\mathrm{c}}$ \\
\hline Age (years) & $29.4 \pm 9.1$ & $29.3 \pm 8.7$ & $29.7 \pm 7.6$ & $31.4 \pm 9.3$ \\
\hline $\operatorname{Sex}(M / F)$ & $14 / 8$ & $6 / 5$ & $15 / 1 \overline{1}$ & $24 / 12$ \\
\hline Baseline BPRS & $36.4 \pm 8.9$ & $43.0 \pm 8.3$ & $36.7 \pm 10.4$ & $34.9 \pm 9.5$ \\
\hline \multicolumn{5}{|l|}{ Dose (mg/kg/day) } \\
\hline Haloperidol & $0.36 \pm 0.06$ & $0.37 \pm 0.13$ & $\begin{array}{l}0.32 \pm 0.15 \\
(n=19)\end{array}$ & $\begin{array}{l}0.48 \pm 0.13^{\mathrm{b}} \\
(n=26)\end{array}$ \\
\hline Flupenthixol & & & $\begin{array}{l}0.26 \times 0.11 \\
(n=8)\end{array}$ & $\begin{array}{l}0.29 \pm 0.08 \\
(n=11)\end{array}$ \\
\hline \multicolumn{5}{|l|}{ Plasma level ( $\mathrm{ng} / \mathrm{ml})$} \\
\hline Haloperidol & $18.7 \pm 7.0$ & $16.0 \pm 6.7$ & $\begin{array}{l}16.4 \pm 10.9 \\
(n=19)\end{array}$ & $\begin{array}{l}25.9 \pm 13.5^{\mathrm{a}} \\
(n=26)\end{array}$ \\
\hline Flupenthixol & & & $\begin{array}{l}3.8 \pm 1.7 \\
(n=8)\end{array}$ & $\begin{array}{l}4.8 \pm 1.3 \\
(n=6)\end{array}$ \\
\hline Improvement BPRS $(\%)$ & $73.2 \pm 14.0$ & $25.6 \pm 13.9^{d}$ & $75.4 \pm 15.6$ & $11.2 \pm 19.7^{\mathrm{d}}$ \\
\hline
\end{tabular}

Fixed-dose: haloperidol $20 \mathrm{mg} /$ day.

Variable-dose: haloperidol 10-30 mg/day; flupenthixol 6-24 mg/day.

pHVA: plasma homovanillic acid; BPRS: brief psychiatric rating scale.

${ }^{\mathrm{a}} p<0.05 ;{ }^{\mathrm{b}} p<0.01 ;{ }^{\mathrm{c}} p<0.005 ;{ }^{\mathrm{d}} p<0.0001$.

antipsychotic treatment. This is in accord with the findings of several previous investigations (Bowers, 1991; Bowers et al. 1984, 1987; Chang et al., 1990; Davidson et al., 1991; Mazure et al., 1991). Data obtained from a group of 37 psychotic patients including schizophrenics and nonschizophrenics have been recently reported by Mazure et al. (1991). Using a pHVA level of $12 \mathrm{ng} / \mathrm{ml}$ as a demarcation point, these investigators found that $75 \%$ of patients ( 14 of 20 ) who had pHVA $\geqslant 12$ responded whereas two-thirds (12 of 17) who had pHVA $<12$ did not respond. Our results are remarkably consistent with these carlicr results: $72 \%$ of patients ( 34 of 47 ) who had higher pHVA levels $(\geqslant 12 \mathrm{ng} / \mathrm{ml})$ responded while $65 \%$ of patients (31 of 48) who had lower pHVA levels $(<12 \mathrm{ng} / \mathrm{ml})$ did not (Table 2).

A study of Pickar et al. (1984) found that schizophrenic patients who responded to fluphenazine treatment had higher pretreatment pHVA levels than normal subjects. In a study from another center, Davidson and Davis (1988) reported that treatment-resistant patients had lower pHVA levels than controls. Although we did 
not have a matched group of normal controls, our results are generally consistent with these combined findings. Taken together, studies support the notion that higher pretreatment pHVA levels in schizophrenic patients are associated with good clinical response to neuroleptics, whereas lower pHVA may be related to poor responsc.

In other respects, our results differ from those reported by the two just cited research groups. Significant positive correlations between baseline pHVA levels and symptom severity have been reported by Pickar et al. (1984), Davis et al. (1985), and Davidson and Davis (1988). We did not find a significant relationship between pretreatment pHVA and BPRS score (data not shown). In this respect, our findings are more consistent with two other reports (Javaid et al., 1990; Mazure et al., 1991). This discrepancy among studies may be attributable to differences in patient populations and methods of symptom assessment. However, if baseline pHVA is generally correlated to symptom severity, it is hard to understand how mean baseline pHVA level in subgroups of schizophrenic patients who appear equally severely ill prior to treatment can be both higher and lower than in normal controls as reported by Pickar et al. (1984) and Davidson and Davis (1988), respectively.

There is far less discrepancy regarding the correlation between pHVA change and clinical response following antipsychotic treatment reported by a number of groups (Bowers et al., 1984; Pickar et al., 1984, 1986; Davidson et al., 1987, 1991; Chang et al., 1988, 1990; Davila et al., 1988; Mazure et al., 1991). Most investigators find that a time-dependent decrease in concentrations of pHVA is correlated with clinical improvement in response to antipsychotics, while no decrease in pHVA is associated with poor clinical response (Bowers et al., 1984; Pickar et al., 1984, 1986; Chang et al., 1988, 1990; Davila et al., 1988; Davidson et al., 1991; Mazure et al., 1991).

Combined, the various results suggest that a high pretreatment pHVA concentration followed by a relatively large decrease on antipsychotics reflect biochemical processes that play an important role in determining therapeutic response. A possible explanation of the differences in basclinc pHVA level and pHVA change during long-term antipsychotic treatment between good and poor responders might be that the syndrome of schizophrenia is biochemically heterogeneous.

On the basis of the differential pretreatment pHVA levels and pHVA changes during chronic administration of antipsychotics as well as the different clinical responses to neuroleptic treatment, we suggest that at least two biologically distinct subtypes can be differentiated among schizophrenic patients: the first would be related to some forms of increased DA activity, and the second one would not. The two subtypes would be in accord with those identified by clinical symptoms (positive and negative), responses to antipsychotic treatment (good and poor), and brain structures determined by computed tomography (without and with brain atrophy) (Crow, 1980, 1985), with the additional characteristics of functional activities in dopaminergic neurons and/or DA synthesizing cells as manifested by pretreatment pHVA levels (high and low), and pHVA changes during long-term antipsychotic treatment (decrease and no decrease). Our results could be interpreted as in accord with the suggestion of Friedhoff $(1986,1988)$ and Davila (1989) that there may be a DA-dependent restitutive or buffer system for the maintenance of mental stability that reduces dopaminergic activity in the face of mentally destabilizing biological or psychological insults. Patients with evidence of high pretreatment dopaminergic activity (if this produces high pHVA) respond well to neuroleptics correlated with pHVA decrease, because antipsychotic mcdication is believed to exercise its therapeutic effect by decreasing dopaminergic activity. In contrast, those with low pretreatment DA function (thus low pHVA) have a poor therapeutic response associated with no decrease in dopaminergic activity, as it has already been downregulated by the stabilizing or restitutive system. Our hypothesis also is not inconsistent with the dopamineserotonin hypothesis as suggested by Meltzer (1989). Treatment-resistent patients who have low baseline pHVA may response to atypical antipsychotics (e.g., clozapine). Measurement of pHVA may be a useful tool for drug choice in the treatment of schizophrenia. Patients with high pHVA can be treated with classical antipsychotics, while those with low pHVA may be need an atypical antipsychotic treatment.

The shortcomings of this study are evident. Data 
gathered over a long period of time ( 5 years) is subject to potential errors. Some investigators have found that seasonal variations in HVA in cerebrospinal fluid and post-mortem brain may exist in humans (Karson et al., 1984; Losonczy et al., 1984). The possibility of a seasonal fluctuation in pHVA levels should be considered (Chang et al., 1993). Moreover, several studies have reported that pHVA and plasma 3-methoxy-4-hydroxyphenyl glycol, a metabolite of norepinephrine, are correlated (Bowers et al., 1984, 1897; Chang et al., 1990). These phenomena suggest the possibility that observed variations in pHVA are contributed by peripheral sources (Amin et al., 1992). For instance, the stress induced by admission might cause an elevation in plasma catecholamine metabolites in some subsets of subjects. Future studies should include efforts to cross these other possible sources of variance in pHVA.

\section{ACKNOWLEDGEMENTS}

The authors acknowledge Huey-Fang Chang, Huey-Jen Chang, Ho-Sheng Wu, Shu-Swei Jaw, and Dong-Juiing Juang for technical collaboration; Yuen-Lih Yeh for statistical analysis; and William $Z$. Potter for his comments on the eirlier version of this manuscript. This work was supprorted by grants NSC 81-0412-B109-501 from the National Science Council and the Taipei City Government.

\section{REFERENCES}

American Psychiatric Association (Ed.) (1980) Diagnostic and Statistical Manual of Mental Disorders, 3rd edn. APA, Washington DC, pp. 181-193.

Amin, F., Davidson, M. and Davis, K.L. (1992) Homovanillic acid measurement in clinical research: a review of methodology. Schizophr. Bull. 18, 123-148.

Bowers, M.B. (1991) Characteristics of psychotic inpatients with highor low HVA levels at admission. Am. J. Psychiatry $148,240-243$.

Bowers, M.B., Swigar, M.E., Jatlow, P.I. and Goicoechea, N. (1984) Plasma catecholamine metabolites and early responseto haloperidol. J. Clin. Psychiatry 45, 248-251.
Bowers, M.B., Swigar, M.E., Jatlow, P.I., Hoffman, F.J. and Goicoechea, N. (1987) Early neuroleptic response: clinical profiles and plasma catecholamine metabotites. J. Clin. Psychopharmacol. 7, 83-86.

Chang, W.-H., Chen, T.-Y., Lee, C.-F., Hung, T.-C., Hu, W.H. and Yeh, E.-K. (1988) Plasma homovanillic acid levels and subtyping of schizophrenia. Psychiatry Res. 23, 239-244.

Chang, W.-H., Chen, T.-Y., Lin, S.-K., Lung, F.-W., Lin, W.L., Hu, W.-H. and Yeh, E.-K. (1990) Plasma catecholamine metabolites in schizophrenics: evidence for the two-subtype concept. Biol. Psychiatry 27, 510-518.

Chang, W.-H., Lin, S.-K., Jann, M.W., Lam, Y.W.F., Chen, T.-Y., Chen, C.-T., Hu, W.-H. and Yeh, E.-K. (1989) Plarmacodynamics and pharmacokinetics or haloperidol and reduced haloperidol in schizophrenic patients. Biol. Psychiatry 26, 239-249.

Chang, W.-H., Lin, S.-K., Juang, D.-J., Chen, L.-C., Yang, C.-H., Lane, H.-Y. and Jann, M.-W. (1993) Effects of haloperidol decanoate on plasma homovanillic acid in chronic schizophrenic patients. Biol. Psychiatry 33, 557-559.

Chang, W.-H., Scheinin, M., Burns, R.S. and Linnoila, M. (1983) Rapid and simple determination of homovanillic acid in plasma using high performance liquid chromatography with electrochemical detection. Acta Pharmacol. Toxicol. $53,275-279$

Crow, T.J. (1980) Molecular pathology of schizophrenia: more than one disease process? Br. Med. J. 280, 66-68.

Crow, T.J. (1985) The two-syndrome concept: origins and current status. Schizophr. Bull. 11, 471-486.

Davidson, M. and Davis, K.L. (1988) A comparison of plasma homovanillic acid concentrations in schizophrenic patients and normal controls. Arch. Gen. Psychiatry 45, 561-563.

Davidson, M., Kahn, R.S., Knott, P., Kaminsky, R., Cooper, M., Dumout, K., Apter, S. and Davis, K.L. (1991) Effects of neuroleptic treatment on symptoms of schizophrenia and plasma homovanillic acid concentrations. Arch. Gen. Psychiatry 48, 910-913.

Davidson, M., Losonczy, M.F., Mohs, R.C., Horvath, T.B., Davis, B.M., Powchik, P. and Davis, K.L. (1987) Effects of debrisoquin and haloperidol on plasma homovanillic acid concentration in schizophrenic patients. Neuropsychopharmacology 1, 17-23

Davila, R. (1989) Plasma HVA, neuroleptics, and dopaminergic plasticity. Biol. Psychiatry 25, 1-3.

Davila, R., Manero, E., Zumarraga, M., Andia, I., Schweitzer, J.W. and Fricdhoff, $\Lambda$.J. (1988) Plasma homovanillic acid as predictor of response to neuroleptics. Arch. Gen. Psychiatry $45,564-567$.

Davis, K.L., Davidson, M., Mohs, K.C., Kendler, K.S., Davis, B.M., Johns, C.A., Denigris, Y. and Horvath, T.B. (1985) Plasma homovanillic acid concentration and the severity of schizophrenic illness. Science 227, 1601-1602.

Friedhoff, A.J. (1986) A dopamine-dependent restitutive system for the maintenance of mental normalcy. Ann. N.Y. Acad. Sci. $463,47-52$.

Friedhoff, A.J. (1988) Dopamine as a mediator of a central stabilizing system: comments on the current status of the dopamine hypothesis of schizophrenia'. Neuropsychopharmacology 1, 189-191. 
Javaid, J.I., Sharma, R.P., Janicak, P.G. and Davis J.M. (1990) Plasma HVA in psychiatric patients: longitudinal studies. Psychopharmacol. Bull. 26, 361-365.

Karson, C.N., Berman, K.F., Kleinman, J. and Karoum, F. (1984) Seasonal variation in human central dopamine activity. Psychiatry Res. 11, 111-117.

Korpi, E.R., Phelps, B.H., Granger, H., Chang, W.-H., Linnoila, M. and Wyatt, R.J. (1983) Simultaneous determination of haloperidol and itsreduced metabolite in serum and plasma by isocratic liquid chromatography with electrochemical detection. Clin. Chem. 29, 624-628.

Losonczy, M.F., Mohs, R.C. and Davis, K.L. (1984) Seasonal variations of human CSF neurotransmitter metabolite concentrations. Psychiatry Res. 12, 79-87.

Mazure, C.M., Nelson, J.C., Jatlow, P.I. and Bowers, M.B. (1991) Plasma free homovanillic acid (HVA) as a predictor of clinical response in acute psychosis. Biol. Psychiatry $30,475-482$.
Meltzer, H.Y. (1989) Clinical studies on the mechanism of action of clozapine: the dopamine-serotonin hypothesis of schizophrenia. Psychopharmacology 99, S18-S27.

Overall, J.E. and Gorham, D.R. (1962) The brief psychiatric rating scale. Psychol. Rep. 10, 799-812.

Pickar, D., Labarca, R., Doran, A.R., Wolkowitz, O.M., Roy, A., Breier, A., Linnoila, M. and Paul S.M. (1986) Longitudinal measurement of plasma homovanillic acid levels in schizophrenic patients. Arch. Gen. Psychiatry 43, 669-676.

Pickar, D., Labarca, R., Linnoila, M., Roy, A., Hommer, D. Everett, D. and Paul, S.M. (1984) Neuroleptic-induced decrease in plasma homovanillic acid and antipsychotic activity in schizophrenic patients. Science 225, 954-957.

Wu, H.-S., Tseng, Y.-T. and Chang, W.-II. (1988) Measurement of flupenthixol in plasma by high performance liquid chromatography with electrochemical detection. In: E.-K. Yeh (Ed), Annual Report laipei City Psychiatric Center. TCPC, Taipei, pp. 160-163. 